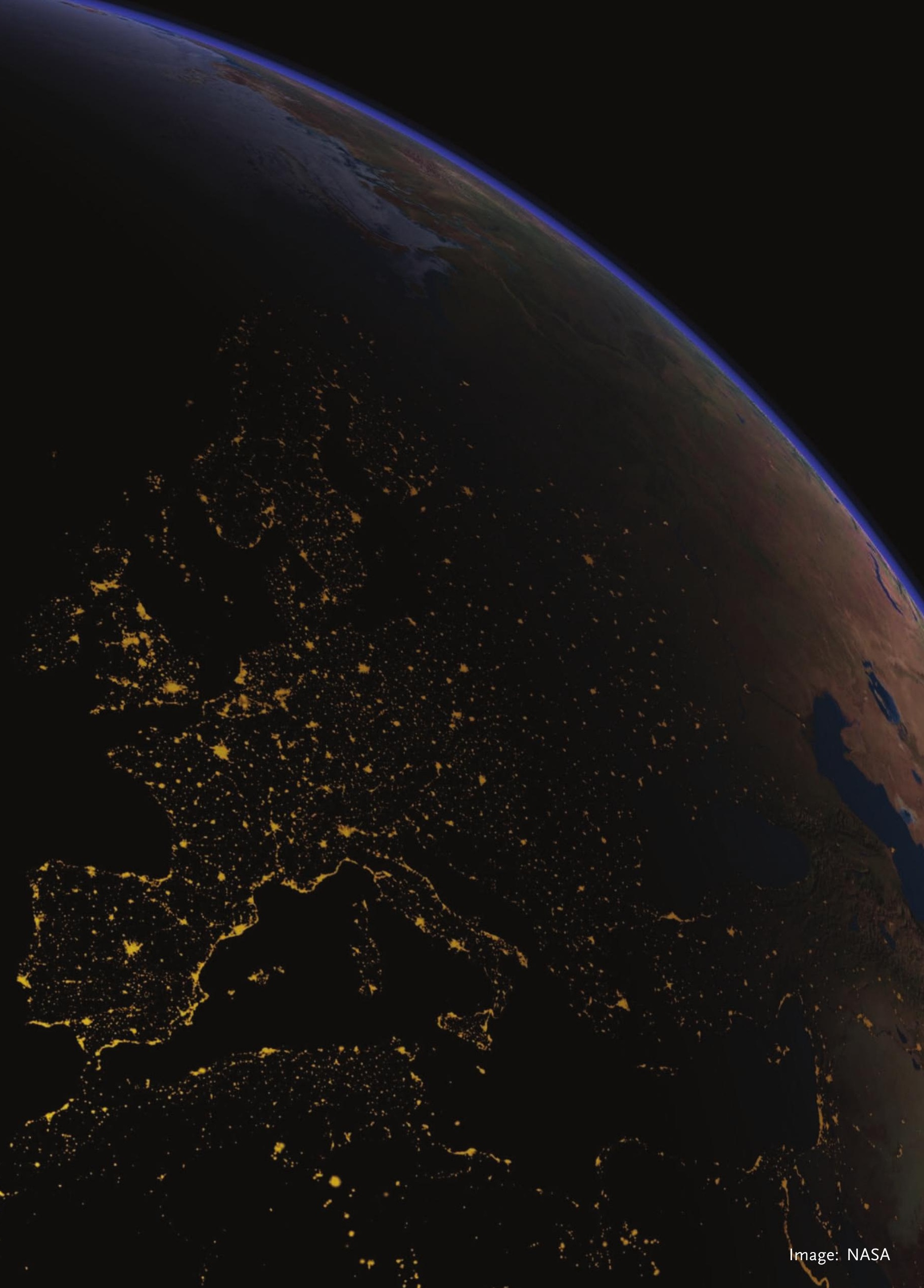




\begin{tabular}{|c|c|c|c|}
\hline$\Omega$ & & $\equiv$ & \\
\hline $\begin{array}{l}\text { Sharon Mitchell, } \\
\text { Anita Simonds, } \\
\text { Stefan Andreas, } \\
\text { Maria R. Bonsignore, } \\
\text { Brendan Cooper, } \\
\text { Viliam Donic, } \\
\text { Walter T. McNicholas, } \\
\text { Mary Morrell, } \\
\text { Paolo Palange, }\end{array}$ & $\begin{array}{l}\text { Gianni Prest, } \\
\text { Renata Riha, } \\
\text { Ha Trang, } \\
\text { Winfried Randerath, } \\
\text { Chris van der Grinten, } \\
\text { Johan Verbraecken, } \\
\text { Wilfried de Backer }\end{array}$ & $\begin{array}{l}\text { Sharon Mitchell, ERS } \\
\text { Headquarters, } 4 \text { Avenue } \\
\text { Ste Luce, } \mathrm{CH} 1003 \text {, } \\
\text { Lausanne, Switzerland }\end{array}$ & sharon.mitchell@ersnet.org \\
\hline
\end{tabular}

\section{Introducing a core curriculum for respiratory sleep practitioners}

\section{Introduction}

The background and purpose of the HERMES (Harmonising Education in Respiratory Medicine for European Specialists) initiative has been discussed at length in previous articles [1-3]. This article aims to provide more detailed and specific insight into the process and methodology of the Sleep HERMES Task Force in developing a core curriculum in respiratory sleep medicine.

\section{The need}

Recently, a number of publications have addressed the evolution of sleep and respiratory sleep medicine as they gain recognition and become an established field of medicine [4-6]. However, continued inconsistencies in the diagnosis, treatment and management of many sleep-related conditions, including obstructive sleep apnoea, have highlighted the need for standards in practice [6], production of guidelines [7] and harmonised training and certification for those practitioners managing patients with sleep-disordered breathing [1, 8].

It was necessary to consider a number of core aspects within sleep medicine during the development of this curriculum, including the varying trends in Europe regarding the practice of this speciality, and whether a curriculum in respiratory sleep medicine should fall under the broader scope of sleep medicine. The recognition of sleep medicine as a sub-specialty in a number of countries, including Australia, the USA and more recently, Germany [7], also impacted on these discussions and led the Sleep HERMES Task Force to establish a working group with members of the European Sleep Research Society (ESRS) during this project phase [9]. Consensus was reached that separate curricula and certification for sleep and respiratory sleep were necessary to reflect current practice in Europe. With a focus on education, this working group will continue to consider commonalities in educating sleep and respiratory sleep practitioners and to develop common educational initiatives in line with the curriculum.

\section{Project background}

The multidisciplinary nature of respiratory sleep medicine has added further complexity to the design of a comprehensive training and certification programme. In practice, respiratory sleep medicine depends not only on the competence of trained medical practitioners but also on that of allied health professionals. This reflects the changing paradigm in
Conflict of interest

S. Mitchell is an employee of ERS. 
medicine as traditional roles break down and there is increasing multidisciplinary treatment of patients and delegation of tasks to those who are competent to perform them [10]. Therefore, the design and development of this curriculum included representatives of the ERS Allied Respiratory Professionals Assembly and is thus accessible not only to medical practitioners but also to advanced practitioners who initiate and lead clinical practice, including nurses and technologists who provide care to the patient.

\section{The curriculum}

\section{Project development}

Harden [11] described a curriculum as more than just a list of content, but rather a refined blend of educational strategies, course content, learning outcomes, educational experiences, assessments, educational environments, learning styles, personal timetables and programmes of work. As ERS professionalises its medical education activity, it has sought to design HERMES curricula that balance complex educational goals with the realities of implementation. To help achieve this balance, the task force began production of educational materials including the ERS Handbook of Respiratory
Sleep Medicine [12], and further educational support materials are planned for the future. Development of assessment methods for certification, including the production of an MCQ-based examination and e-portfolio assessment is also under way. And finally, in accordance with the broader HERMES initiative, educational toolkits for trainers as well as guidance for implementation for training institutions are also planned as future projects to support curriculum implementation.

The first step of a HERMES project is completing a situational analysis to investigate applicability and acceptability within the field. The Sleep HERMES Task Force completed this investigation, the results of which highlighted the heterogeneous models and lack of specific training in many countries across Europe. Following this analysis, the task force began preparation of content to be covered in training: the syllabus to provide harmonised standards for respiratory sleep medicine across Europe [1].

After this milestone, task force members worked together to create a structured approach for training, prescribing learning outcomes and core competencies, as well as assessment methods and learning activities. Following the process set out by PRIDEAUX [13], the final link in the chain addresses the monitoring and evaluation of the curricula, a phase

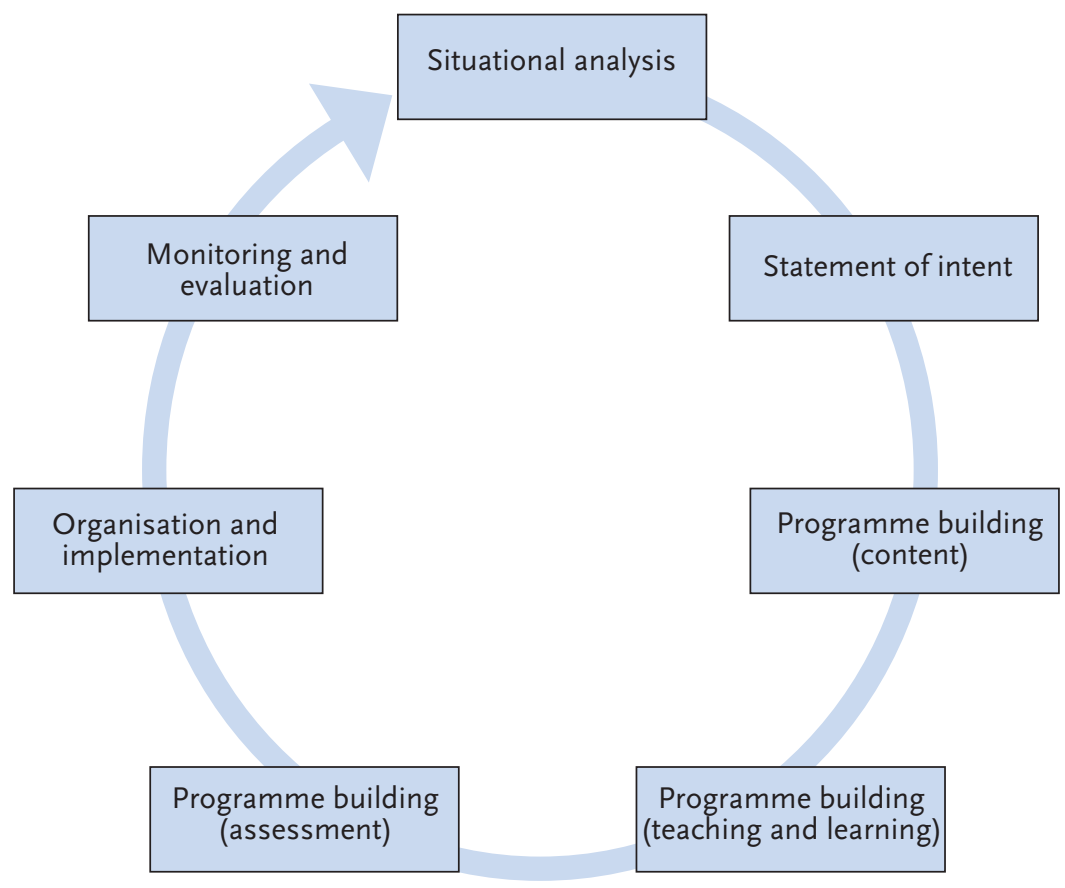

Figure 1

The situational analysis model emphasises the importance of context in curriculum design. 
yet to be designed and structured within ERS (fig. 1).

This curriculum in respiratory sleep medicine is designed to reflect changes in practice as increasing numbers of hospitals and centres establish units dedicated to respiratory sleep disorders. Training is recommended as a 12-month modular programme, including multiple formative and summative assessment methods for certification. Further information on the background of training may be found within the curriculum presented along side the online version of this article at breathe.ersjournals.com.

\section{Collaborators on the project}

During development, the educational task force consisted of 12 ERS members representing eight European countries. The inclusion of allied health professionals in this task force was essential and, after the publication in 2012 of the article "New considerations in project development for the respiratory sleep HERMES" [14], three additional representatives were invited to participate. Each task force member contributed to the writing, review and approval of each of the curriculum modules.

\section{Methodology}

The curriculum defines the learning required during a training programme in terms of knowledge, skills and attitudes necessary for successful completion [15]. The model presented by Prideaux [13] offers a structure and describes a process for design and development with a specific focus on context, while also highlighting important elements for consideration, including content, teaching and learning strategies, assessment processes and evaluation (fig. 1). The HERMES curriculum template has been remodelled to consider each of these important elements.

\section{Programme building: content}

Using the prescribed content and modules published in 2011 [1], the task force set out to identify the core competencies required for each specific module. These modular competencies helped to guide task force members in determining the knowledge, skills and attitudes required for training. The curriculum content reflects the tasks required of the learner after training is complete [15]. Specific actions have also been incorporated to ensure that each learning outcome is measurable and assessable [16].

\section{Programme building: teaching and learning}

Consideration of teaching and learning methods and the environment for learning are inherent in any curriculum although it is notable that often the final decision about the method of learning is left with the teacher [15]. This task force pursued a delicate balance of ensuring that the important area of teaching and learning was addressed without being too restrictive in implementation. This element of the curriculum offers examples of teaching and learning opportunities that may be employed for specific content items.

\section{Programme building: assessment}

Assessment is an integral part of education. In 1990, Miller presented a model of clinical competence to illustrate the need for multiple assessment tools essential to determine whether the clinical practitioner is "competent to practice" [17]. Miller's model placed strong emphasis on the appropriate selection of assessments of factual knowledge (knowing), clinical reasoning and problem solving (knowing how), ability to act appropriately

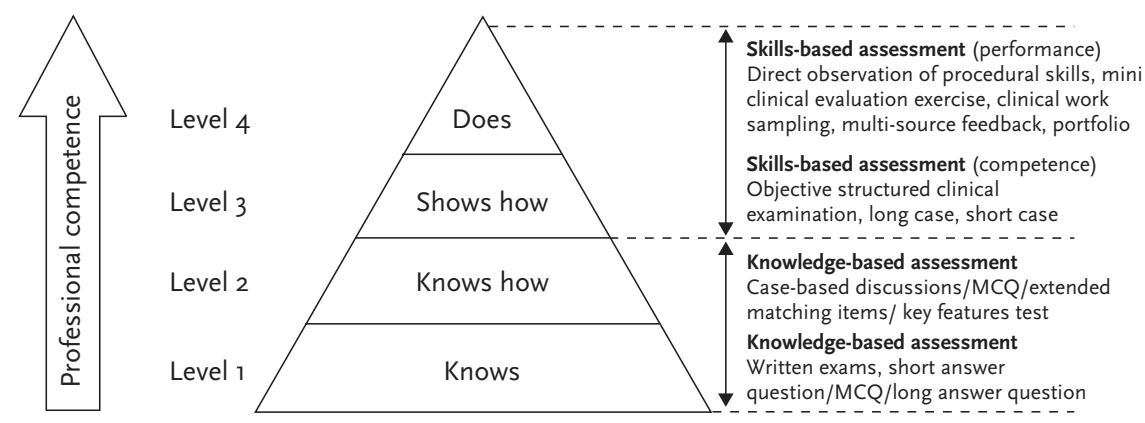

Figure 2

Miller's Model of clinical competence. Reproduced from [17] with permission from the publisher. 
in a practical situation (showing) and actual performance in habitual practice (doing) [18] (fig. 2). While Miller's model helped to identify the level of assessment, ZuBair et al. [19] have clearly organised methods of assessment according to Miller's prescribed levels. Using this model, the task force considered the prescribed learning outcomes in various contexts and identified possible assessment methods for use. The focus here was on the use of multiple methods, both formative and summative.

The result of this process comprises the respiratory sleep HERMES curriculum.

\section{Discussion}

\section{Interprofessional education}

Despite the absence of consensus on the definition of teamwork and interchangeable use of the terms multidisciplinary, multiprofessional and interprofessional within healthcare [20], the beneficial role of teamwork in improving patient care is repeatedly reported in the literature [20-22]. For the first time within the HERMES initiative, this project task force sought to build a common curriculum framework to ensure acquisition of competencies for all medical practitioners and allied health professionals working in respiratory sleep medicine. The intention is to replace different training structures with one combined programme for training and certification in respiratory sleep medicine. This bold undertaking by the task force has addressed some of the barriers hindering teamwork previously mentioned in the literature, such as the different levels of skills acquisition within a team [20]. With the support of the Sleep HERMES Task Force, this common framework is intended to guide healthcare professionals to prepare for the next steps in implementation: delivery of instructional methods, learning, supporting resources, assessment methods, educational toolkits and faculty development.

Achieving the educational standards set out within the curriculum for the target audience is confined by the diversity of legal frameworks across countries. It is still hoped, however, that this curriculum will achieve its long-term goal of safeguarding practice in respiratory sleep medicine and assuring quality of education for those practitioners managing patients with respiratory sleep disorders.

\section{Levels of assessment}

Since 2008, each HERMES project task force has used levels of competence to distinguish the targeted level of performance required of the trainee at the end of their training programme. With the added complexity of multidisciplinary team curricula, this has become more complex.

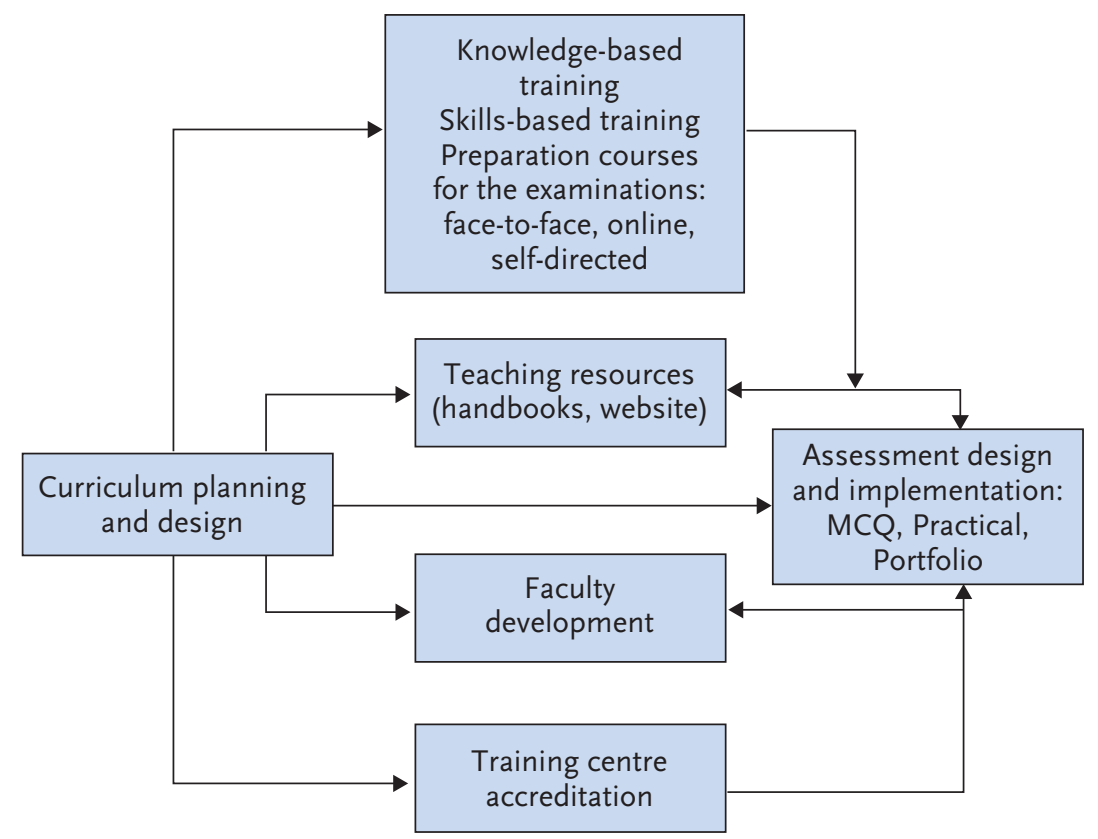

Figure 3

Implementation structure for harmonisation of training. 
With the advice and support of medical education advisors, and with the use of Miller's model of clinical competence, these levels of competence have been modified to illustrate the level of assessment and to help guide training institutions on the types of assessment methods to be used for each syllabus item. The assessment therefore represents a reasonable indication of an individual's ability to perform in practice [23]. Miller's model distinguishes between assessment methods as well as giving consideration to where assessment should take place, whether in a controlled assessment environment or in the setting of daily work [24].

\section{Conclusion}

The advantages of setting educational standards for postgraduate medical training at an international level must not be underestimated. Standards provide educators, practitioners, regulators and accreditors with a clear purpose to stimulate improvements, benchmark performance, assure minimum criteria and safeguard practice [25]. The HERMES model (fig. 3) offers a structure not only to develop a core curriculum for training but also establish key educational activities to support curriculum implementation. Current plans within the project's scope are to build an assessment framework, as well as specific assessment tools including an MCQ knowledge test and e-portfolio assessment. The e-portfolio project falls under the broader ERS educational initiative to develop an e-portfolio for members. Supporting documents, including toolkits for curriculum implementation and faculty-development courses are also being considered within the HERMES initiative. In presenting a common curriculum for medical and allied health professionals alike it is hoped that all those working in respiratory sleep medicine will feel equipped with the necessary skills to function as a team member and support changes in practice towards collaborative patient-centred care.

\section{Acknowledgements}

The Sleep HERMES Task Force would like to thank Griet Peeraer (University of Antwerp, Antwerp, Belgium) for her valued recommendations on how to improve the curriculum design and planning. Further acknowledgement must also go to the Education Council directors who are actively involved in overseeing all HERMES projects, Ernst Eber (Medical University of Graz, Graz, Austria), HERMES director and Konrad Bloch (University Hospital Zurich, Zurich, Austria), assessments director. Finally a word of thanks to the ERS Education Council Chair Gernot Rohde (Maastricht University, Maastricht, the Netherlands) whose support for HERMES and specifically the Sleep HERMES Task force has ensured that this important milestone has been reached.

Author affiliations: Sharon Mitchell: European Respiratory Society, Lausanne, Switzerland. Anita Simonds: Academic Department of Sleep and Breathing, Royal Brompton Hospital, London, UK. Stefan Andreas: Lungenfachklinik Immenhausen, Immenhausen, Germany. Maria R. Bonsignore: University of Palmero, Palermo, Italy. Brendan Cooper: Lung Function and Sleep, University Hospitals Birmingham NHS Foundation Trust, Queen Elizabeth Hospital Birmingham, Birmingham, UK. Viliam Donic: Medical Faculty, Faculty of Medicine, Pavol Jozef Safarik University, Košice, Slovakia. Walter T. McNicholas: Respiratory Sleep Disorders Unit, St. Vincent's University Hospital, Dublin, Ireland. Mary Morrell: Clinical and Academic Unit of Sleep and Breathing, National Heart and Lung Institute, Imperial College London, London. Paolo Palange: Dipartimento di Medicina Clinica, "La Sapienza" University, Rome, Italy. Gianni Prest: S.C. Pneumologia, ASL 1, Imperia, Italy. Renata Riha: Royal Infirmary Edinburgh, University of Edinburgh, Edinburgh, UK. Ha Trang: Department of Physiology, University of Paris, Paris, France. Winfried Randerath: Bethanien Hospital, Institute of Pneumology, University Witten/Herdecke, Solingen, Germany Chris van der Grinten: Department of Respiratory Medicine, Maastricht University Medical Center, Maastricht, The Netherlands. Johan Verbraecken: Department of Pulmonary Medicine and Multidisciplinary Sleep Disorders Centre, Antwerp University Hospital and University of Antwerp, Antwerp, Belgium. Wilfried de Backer: Respiratory Medicine, Antwerp University Hospital, Edegem, Belgium.

\section{References}

1. De Backer W, Simonds A. Sleep HERMES: A European core syllabus in respiratory disorders during sleep Breathe 2011; 8: 61-68.
2. Pitta F, Mitchell S, et al. A core syllabus for post-graduate training in respiratory physiotherapy. Breathe 2014; 10: $221-228$. 
3. Mitchell S, Bloch KE, Butienne I, et al. 'Education is the passport to the future' - Enabling today's medical teachers to prepare tomorrow's respiratory health practitioners'. Eur RespirJ 2014; 44: 578-584.

4. The Royal Australasian College of Physicans. Sleep Medicine: Advanced Training Curricululm. Available from http://handbooks.racp.edu. $a u / ? y=2013 \# /$ respiratory-medicine-and-sleep-medicine/2014/summary/o Date last accessed: January 12, 2015.

5. BaHammam AS, Al-Jahdali $\mathrm{H}$. Saudi regulations for the accreditation of sleep medicine physicians and technologists. Ann Thorac Med 2013; 8: 3-7.

6. Parthasarathy $\mathrm{S}$, Haynes $\mathrm{PL}$, et al. A national survey of the effect of sleep medicine specialists and american academy of sleep medicine accreditation on management of obstructive sleep apnea.J Clin Sleep Med 2006; 2: 133-142.

7. Pevernagie D, Stanley N, et al. European guidelines for the certification of professionals in sleep medicine: report of the task force of the European Sleep Research Society. J Sleep Res 2009; 18: $136-141$.

8. ATS/ASDA/ACCP/APCCMPD Statement about training of pulmonary physicians in sleep disorders. American Thoracic Society Archives. Available from www.thoracic.org/statements/resources/archive/ sleeptraining1-5.pdf Date last accessed: January 12, 2015.

9. McNicholas WT, Bassetti CLA. Sleep and breathing disorders: a multidisciplinary approach. Eur Resp J 2013; 22: 197-198.

10. Ten Cate OT, Snell L, Carraccio C. Medical competence: The interplay between individual ability and the health care environment. Med Teach 2010; 32: $669-675$.

11. Harden RM. AMEE Guide No. 21: Curriculum mapping: a tool for transparent and authentic teaching and learning. Med Teach 2001; 23: 123-137.
12. Simonds A.K. and de Backer W. Eds. ERS Handbook of Respiratory Sleep Medicine. Sheffield, ERS, 2012.

13. Prideaux D. ABC of learning and teaching in medicine - Curriculum design. BMJ 2003; 326: 268.

14. De Backer W, Mitchell S on behalf of the respiratory sleep HERMES Task Force. Respiratory Sleep HERMES: new considerations in project development. Breathe 2012; 9: 85-8.

15. McKimm J. Curriculum and course design. Clinical teaching made easy. BrJ Hosp Med 2009; 70: 714-717.

16. Blanchard NP, Thacker JW. Effective Training: Systems, Strategies, and Practices $5^{\text {th }}$ Edn. New Jersey, Brooks Hill-Whilton, 2013.

17. Miller GE. The assessment of clinical skills/ competence/performance. Acad Med 1990; 65: 63-67.

18. Van der Vleuten $C$. Validity of final examinations in undergraduate medical training. BMJ 2000; 321: 1217-1219.

19. Zubair A, Seng CY, Eng KU. Practical Guide to Medical Student Assessment. Singapore, World Scientific Publishing, 2006.

20. Atwal A, Caldwell K. Nurses' perceptions of multidisciplinary team work in acute health-care. Int J Nurs Pract 2006; 12: 359-365.

21. Bainbridge L, Nasmith L, Orchard C. Competencies for interprofessional collaboration.J Phys Ther Educ 2010; 24: 6-11.

22. Jazieh AR, Abdulrahman, AH, Howington J. Thoracic oncology multidisciplinary teams: Between the promises and challenges. Ann Thorac Med 2008; 3: 34-37.

23. Ker J, Bradley P. Simulation in medical education. In Swanwick T, ed. Understanding medical education. Oxford, UK, Wiley-Blackwell, 2010.

24. Norcini J. Workplace assessment. In: Swanwick T, ed. Understanding medical education. Oxford, UK, Wiley-Blackwell, 2010.

25. Lilley P, Harden R. Standards in medical education. Med Teach 2003; 25: 349-351. 